\title{
MSW MANAGEMENT IN SÃO PAULO CITY AND THE NATIONAL POLICY OF SOLID WASTE
}

\author{
Veronica R. Polzer \\ PhD student of Mackenzie University, São Paulo, Brazil \\ Department of Architecture and Urbanism \\ Scholarship from CAPES Foundation - Process: 5550-14-9 \\ Department of Building \& Environmental Technology \\ Division of Water Resources Engineering \\ Lund University, Sweden \\ Corresponding author: veronica.polzer@tvrl.lth.se \\ Kenneth M. Persson \\ Department of Building \& Environmental Technology \\ Professor of Division of Water Resources Engineering \\ Lund University, Sweden
}

\begin{abstract}
The objective of this paper is to present a brief overview of the current situation of solid waste in Brazil, as well as the importance of the National Policy of Solid Waste as the main regulatory milestone of the country, clarifying the role of society, government and the private sector. Moreover, this law is essential for determining the closing of dumps, encouraging municipal consortia and establishing a hierarchy for solid waste management through waste reduction at source, reuse, recycling, energy recovery and disposal. Also it aims to understand how São Paulo, the most important city of Brazil, is currently facing the problem and what are the scenarios and proposals indicated in the Integrated Management Solid Waste Plan of the city to get the sustainable solid waste management of São Paulo in operation.
\end{abstract}

\section{KEYWORDS}

Municipal Solid Waste Management; Public Policies; Urban sustainability; Recyclable collection

\section{INTRODUCTION}

The problem of municipal solid waste (MSW) management has always existed in Brazilian cities but in recent decades the subject has become an important theme in debates and environmental movements, achieving greater prominence among other public policies since the generation of solid waste has increased significantly in the cities the last 20 years. The 
existence of dumps yet, the lack of incentive campaigns to reduce waste at source, little incentive recycling and composting are worrying factors for a developing country with many challenges to be faced.

Daily the country buries in their landfills and dumps recycled materials of high economic value that could generate income and jobs through recycling industries. Not only recyclable material that ceases to be tapped but also organic waste that could generate energy and compost to be used in agriculture, gardening, landscaping, erosion control and other uses are currently not used in a sustainable way. Graphic 1 indicates the average gravimetric composition of solid waste from a typical Brazilian. It is possible to observe that the organic portion is representative, constituting more than half of the solid waste produced, and this portion may increase in poorer areas and decrease significantly in wealthy areas. For calculation purposes the numbers were considered represented in the graph, but each locality must be studied separately in order to obtain a correct diagnosis and consequently deploy the most appropriate treatment alternatives, consistent with the study area. Remembering that Brazil is a country of great contrasts and decisions taken in a particular location cannot serve for another.

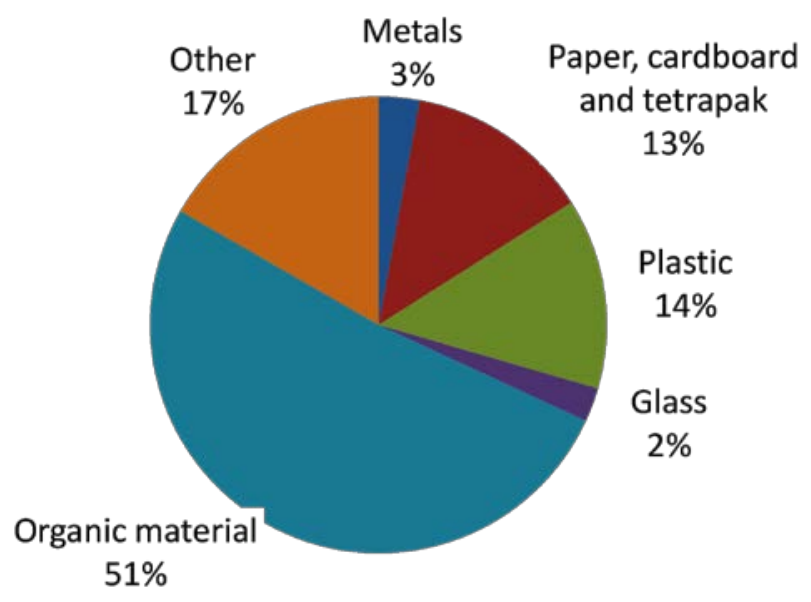

Graphic 1 - Gravimetric composition of MSW in Brazil. [2,4]

According to the National Survey of Basic Sanitation in 2008 Brazil allocates its solid waste to 1723 landfills, 1130 controlled landfills, which are improved dumps and 2906 dumps, which means that more than $50 \%$ of solid waste collected is disposed of inappropriate sites. [1] In addition, the selective collection programs for recyclable materials assist only $14 \%$ of Brazilian municipalities, representing 766 cities [3]. As further aggravate the situation, about 20,000 tons of solid waste ceases to be collected throughout the country daily.

The recyclable collection in the country occurs in most cases, with some exceptions, informally, by autonomous scavengers who collect recyclable materials, which have economic value for resale. This activity occurs primarily as a result of the population's need in achieving income through commercialization of these materials and not due to environmental awareness. Only a few cities and neighborhoods have infrastructure for collection and separation of recyclable materials in a more formal and efficiently manner. As aggravating factor dumps are places where most scavengers remove recyclable materials in an environment considered extremely hostile which constitutes a significant risk to public health. 
According to the trade organization ABRELPE (Brazilian Association of Public Cleaning and Special Waste) in 2013 were generated 76.4 million tons of waste in the country, representing an increase of $4.1 \%$ over the previous year. The generation of waste is growing at a higher pace than the population, which from 2012 to 2013 was 3.7\%, in other words, the increased amount of waste generated per capita was $0.39 \%$. Important to note is that the amount of waste collected daily also increased from 181288 tons in 2012 to 189219 tons in 2013. This increase in waste generation can be associated with a favorable economic time of full employment, with the unemployment rate recorded is only 5.4\% in 2013 and increased consumption through policies implemented by the government as the "bolsa-família", which stimulates consumption by the poorest people, heating the economy. Despite a relative improvement in the quality of life the basic infrastructure, transport, health, housing, sanitation and education are still lagging behind. [2]

\section{NATIONAL POLICY OF SOLID WASTE}

The management of solid waste has been one of the most debated and the object of great current discussions in Brazil. The National Policy of Solid Waste, Law number 12,305 of August 3, 2010, took 20 years to be enacted. It is considered the main regulatory milestone of the country and had as the legal basis three main instruments: the Public Consortia Law (Law number 11,107/2005), Decree-Scavenger Pro (Law number 7404/2010) and the Basic Sanitation Law (Law number 11.455/2007). The law requires all municipalities, consortium areas and states to deliver until August 2012 their Integrated Management of solid waste plans and until August 2014 that all municipalities close down their dumps. Municipal governments were able to deliver their management plans but the dumps are far to cease the reception of solid waste and still remain in operation despite that the deadline has expired. [4]

The National Policy of Solid Waste clarified some definitions already used in previous legislation and inserted new concepts such as the distinction between waste and residues. The first is related to materials that can still be reused and recycled and the second those that cannot be recycled or composted and therefore should be forwarded to the final destination, which may be a landfill or waste-to-energy facility. This distinction between waste and residues was fundamental to oblige the waste has another destination than the current, the landfills. The next step after the implementation of infrastructure needed for recycling and composting would be to ban recyclable, organic and special waste from landfills. [4]

The law is also important because it requires that municipalities determine their aims, scenarios and goals in the short, medium and long-term in their management plans. As well as include cooperatives of scavengers, deploy differentiated collections for recyclables and organic materials and seek consortia bringing together various municipalities and reducing costs of operation and maintenance of landfills and other solid waste equipment. The most important is that all agents are engaged, society, government and the private sector so that the guidelines and objectives stated in the plan will be achieved.

Through the law companies will be able to seek tax and financial incentives for the implementation of reverse logistics policies, encouraging the return of post-consumer products for recycling and reuse. For each product, it is necessary to analyze their life cycle and recovery and recycling alternatives after use, as well as, the logistics to collect and transport the material to its destination. 
Regarding autonomous and scavengers cooperatives the law is crucial to ensuring that they are part of the system and work in a formal way and also that there is an increase in the allocation of this material for recycling, diverting them from landfills and still generating jobs and income throughout the solid waste management chain.

\section{MSW MANAGEMENT IN SÃO PAULO CITY}

The city of São Paulo is considered as the financial center of the country, representing $12.26 \%$ of the Brazilian GDP and being 10th largest GDP in the world with $63 \%$ of multinational companies established in the country and the sixth largest stock exchange in the world. Furthermore, São Paulo is the sixth largest city in the world and the fourth largest urban agglomeration, with approximately 18 million people living in its metropolitan area. It is also known to be a cosmopolitan city, home to more than seventy different ethnicities and cultures, which also makes it an extremely complex city with major challenges to overcome in all public policies. [6]

\subsection{Diagnosis}

The city of São Paulo with 11.253 .500 inhabitants, living in 32 boroughs, on average generates about 18.000 tons of solid waste daily, composed as follows:

- Household: 52,82\%

- Recyclables: $1,05 \%$

- Inert (construction and demolition): $25,60 \%$

- Streets sweeping: $1,36 \%$

- Health: 0,49\%

- Miscellaneous (several sources): 18,68\% [5]

Regarding to MSW collection, two companies are responsible for the household waste collection being Ecourbis responsible for 19 boroughs in southeastern and Loga responsible for 13 boroughs in the northwest region. The waste collected is sent to three transfer stations (Vergueiro, Ponte Pequena and Santo Amaro) and from there proceed to the two landfills, one public, CTL (Central Eastern Wastes Treatment) and another one private in the city of Caieiras, São Paulo metropolitan region (see flowchart in Figure 1).

In relation to recyclables materials collected by the city, these are directed to the 22 recycling sorting cooperatives registered, one being specific to electronic waste. The city also has 76 ecopoints receiving construction and demolition waste, recyclable, leftover paint, varnishes, glues and other toxic materials. The 12,113 large generators ${ }^{1}$ of solid waste, recorded at City Hall, need to hire a private collection service and cannot use the public services of solid waste collection. [5]

Also in relation to the collection of solid waste, the city has 1631 registered housing locations with difficult access [5], which represents areas with needs of urbanization, in general are slums and other poor squatter settlements, near hillsides, riverbeds and other public areas. The difficulties of access for solid waste collection make the population dispose their garbage in inappropriate places. In order to combat these points of irregular disposal, the government created the ecopoints, but these are still insufficient and located far from many communities. The two companies that collect solid waste in housing areas with difficult access, especially

\footnotetext{
${ }^{1}$ Large generators of solid waste are trades and institutions that generate more than 200 liters daily, in the case of waste or $50 \mathrm{~kg}$ daily of inerts. [8]
} 
slums, have employed people from the same area due to their familiarity with the neighborhood. Through a container with wheels, the employee can pass through the narrow alleys and then discharge into a bucket where the truck has access to bring the waste to a transfer station.

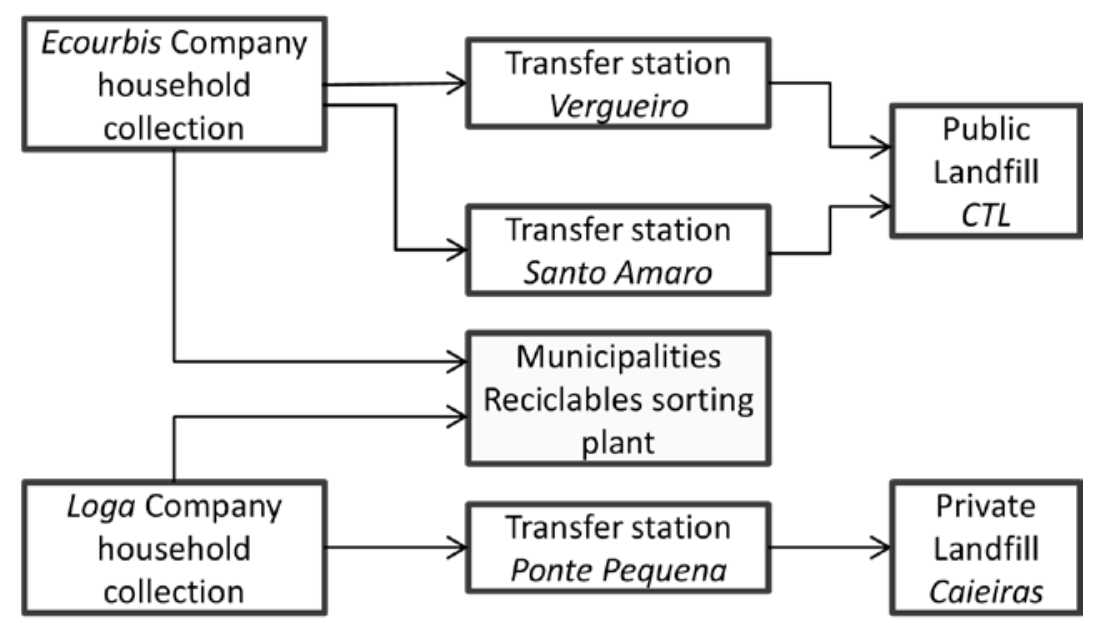

Figure 1 - Flow of household waste in São Paulo city. [7]

In respect the recyclable materials collection, about $40 \%$ of housing units are served by home collection, generating 193 tons per day, which represents $1.05 \%$ of the total collected in the city in 2012. The rest of the residences that are not served by this collection, has alternatively deliver recyclable waste at the point of voluntary delivery, there are 1500 recyclable points and 76 ecopoints [5]. The amount of recyclable materials diverted from landfills could be higher if there were more points of voluntary delivery in, which citizens could walk, or if the collection trucks by city hall were extended to the complete city, also, is needed that environmental awareness campaigns reaches the entire population, starting in schools, institutions, neighborhood associations and by Media.
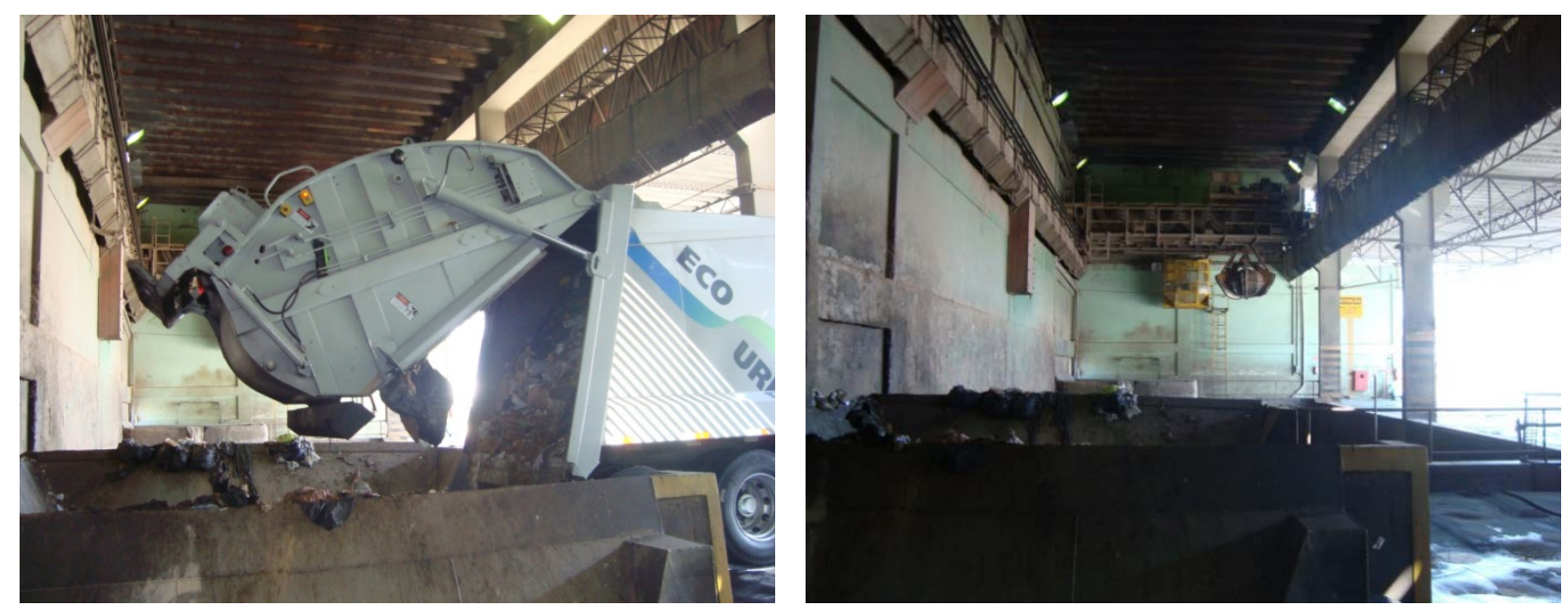

Figure 2 - Transfer station Vergueiro. [9] 
Regarding the transfer stations it is observed that the flow of waste discharge at this location is intense and continuous, in the case of Vergueiro and Santo Amaro units the operation of waste takes place in a covered area but not enclosed, causing discomfort to the surrounding population (see Figure 2). Ideally, this activity is performed in a closed place with negative pressure relative to the external area preventing indoor air contaminating the outside. According to information from concessionaires, the companies hired by the city hall responsible for the waste collection and their final disposal, these areas are operating beyond their capacity. If only the residues were destined for these locations, the amount of waste to be collected and grounded would be much smaller and the capacity of transfer stations would be sufficient.

In São Paulo there are no operation dumps and all the waste is destined for two landfills, CTL and Caieiras. The public landfill, CTL, with a receipt area of approximately $390,000 \mathrm{~m}^{2}$ in a total of $1,123,590 \mathrm{~m}^{2}$, is operated by concessionaire itself hired by the city and began operations in 2010. It is scheduled for closure in 2025. The Caieiras landfill, operated by a private company called Essencis, being the largest landfill in the country with an area of $3,500,000 \mathrm{~m}^{2}$, of which $43 \%$ is covered with vegetation, began operations in 2002 and also has a lifetime of about 15 years. [7]
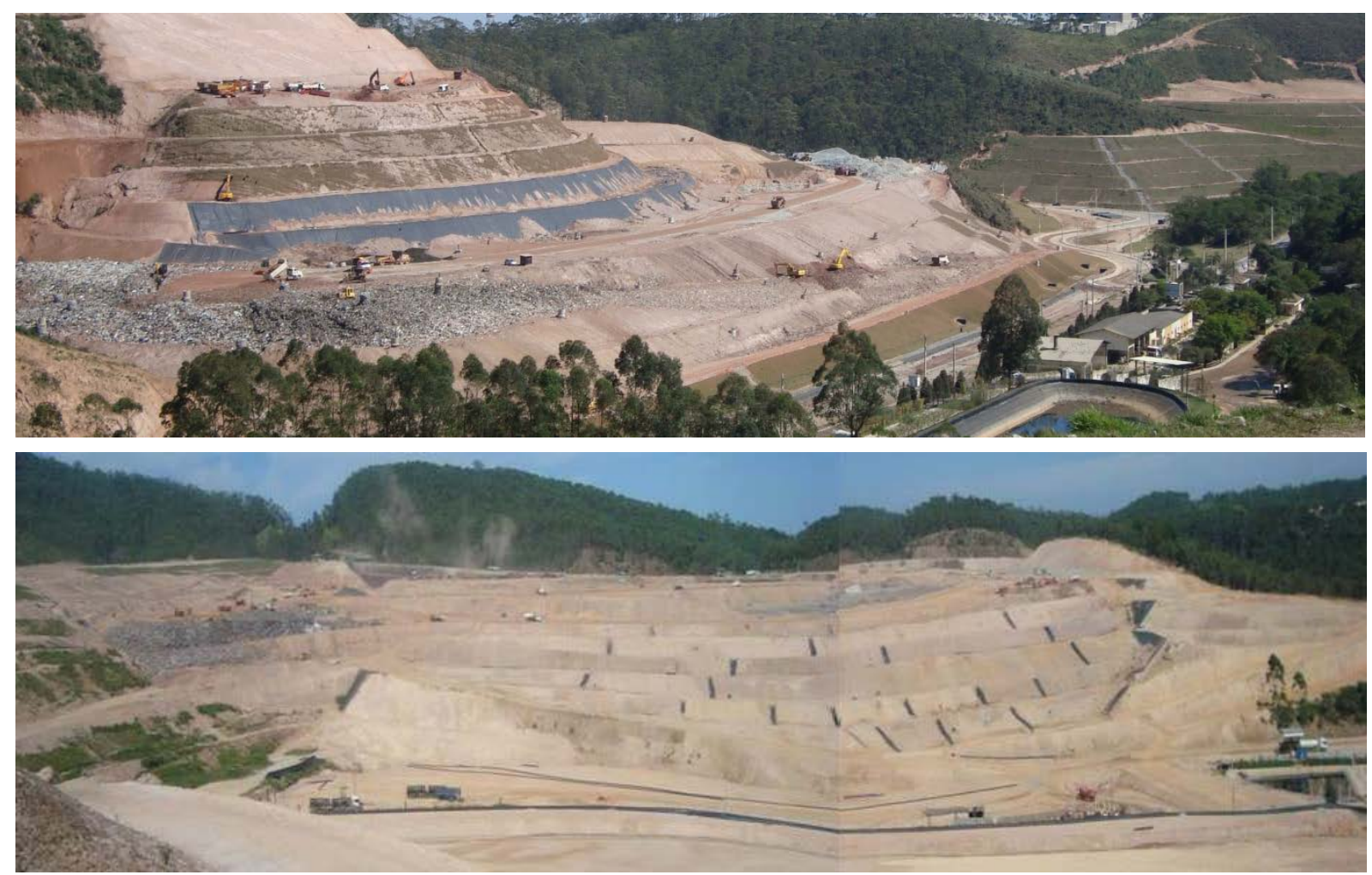

Figure 3 -CTL and Caieiras landfills. [9, 10]

\subsection{Shared responsibility}

According to the plan of solid waste management in São Paulo, all agents involved should share responsibility for the solid waste management and each of them has an important role to obtain the expected results, as follows: 
- The City Hall is responsible for promoting the dissemination of solid waste data to the population, as well as launching awareness campaigns to ensure citizen participation in reducing the generation of waste and proper disposal of the same. Is also responsible for managing the goals and monitor the progress of environmental education programs in the society, measuring the results through the indicators;

- The AMLURB (Municipal Urban Cleaning Authority) is responsible for administering the contracts of companies that perform the cleaning services, ensuring social inclusion of scavengers and measuring the results of the entire chain, in order to follow the evolution of recycling rates and proper disposal;

- The Green and Environment Municipal Department is responsible for the legal assessment, penalizing non-compliant companies and reinvesting the penalties in cooperatives of recyclable materials. Furthermore they are responsible for proposing new laws;

- The Economic Development and Labour Municipal Department is responsible for promoting courses and train scavengers as well as providing subsidies for cooperatives;

- The Education Municipal Department is responsible for encouraging the participation of schools in environmental education programs, especially in relation to sustainable consumption;

- The Boroughs Coordinating Municipal Department is responsible for stimulating the participation of the boards of the environment and sustainable development in developing diagnostics and local proposals for solid waste management, as well as educating the public through campaigns conveyed in the boroughs and strengthen scavengers local networks in order to ensure the quantity and quality of recyclable materials at the point of delivery;

- The Health Municipal Department is responsible to promote the conditions necessary for health and safety for the worker;

- The Social Welfare and Development Municipal Department is responsible for ensuring that the scavengers have the necessary personal documentation and assistance;

- The Urban Development Municipal Department is responsible for promoting discussions on sustainable urban development during the development stages from design to the end of construction;

- The Housing Municipal Department is responsible for providing specific areas to set up recycling containers and collection of recyclable materials according to each project;

- The private companies are responsible for:

o Hiring the scavengers cooperatives for the collection and sorting of recyclable materials;

o Redesigning the product and its packaging to minimize the generation of solid waste;

o Reverse Logistics and proper disposal of waste;

- The residents are responsible for:

o Knowing the law;

o Separating the solid waste properly;

o Delivering the special and construction waste in ecopoints or hire the services of collection when the material exceed the amount allowed in ecopoints;

o Reduce the generation of solid waste at source, as well as reuse, recycle and recover waste;

o Make the payment of fees as current laws. [5]

The law is quite clear about the role of each one in relation to the management of solid waste in the city but it is possible to observe that the actions have not yet entered into force. The collection of recyclable materials is restricted to some neighborhoods. There is no delivery points sufficient for the population, which citizens can walk to one of these sites. Further, on recyclable materials and information campaigns to the population are inadequate and incomplete. Regarding reverse logistics programs it is noted that some programs were 
implemented but were not widely publicized, for instance, the delivery of expired medicines in drugstores, much of the population still discarding these special materials and others as household waste.

The CETESB (Technology Company of Environmental Sanitation), is the representative of the state government, responsible for overseeing the municipalities of São Paulo, review and approve projects for treatment and final disposal of solid waste, as well as guiding technically the cities, review standards, resolutions and environmental legislation. Through the CETESB's reports, the federal government can verify if the municipalities are environmentally adequate or not.

As already mentioned, the federal government through the National Policy of Solid Waste requires municipalities to enclose their dumps, which deadline expired in August 2014. As about $50 \%$ of these municipalities are still irregular, therefore they will not receive federal income for their solid waste management in their locality unless they comply with the law. However, as they cannot afford to collect, treat and dispose of waste in an environmentally adequate way, the federal government is studying case by case seeking specific solutions for each area. For municipalities with less than 20,000 inhabitants the government has supported the formation of public consortia. [13]

\subsection{Prognosis and future situation}

The city of São Paulo has two main objectives in its plan for solid waste management: extend the landfills life with actions to reduce the volume generated at the source and also with actions such as recycling, reuse and composting of organic waste and promoting Environmental Education. To achieve the objectives were established a plan of actions and guidelines including: Improvements in urban cleaning system; Actions to reduce volume and Expansion of public participation. [5]

The following actions are planned to improve the infrastructure of waste management in the city:

- Mechanize part of the solid waste collection through underground containers for large capacity in the greatest generation places. Once the container exhausts its capacity a chip transmits a signal so it can be replaced;

- Expand the special health waste collection vehicles;

- Reform and modernize the Vergueiro transfer station, which is currently precarious and quite uncomfortable for the surrounding population;

- Create new areas for unloading and sorting of construction and demolition waste;

- Create another 84 ecopoints, in total 142, and 18 have already been built. For the size of the city's 76 ecopoints are insufficient and the citizens cannot reach these on foot, being necessary to deploy smaller delivery recyclable points nearer homes;

- Deploy two more units of infectious waste treating, with the goal of reducing the distance between the generators and treatment units;

- Combat irregular points of waste disposal. The city of São Paulo is developing a aerophotogrammetric mapping system to identify irregular disposal points and thus be able to phase them out;

- Create 8 small organic processing plants with capacity to process 50 tons each per day, 4 big plants with capacity to process 600 tons each per day and also 3 units of Mechanical Biological Treatment to process 2,500 tons per day; 
- Create a database that aims to collect data, provide performance indicators, and systematically gather all data to work with all agencies in the integrated solid waste management in the city;

- Construction of 12 more stations for sorting recyclables because the 22 existing stations receive less than $2 \%$ of all waste collected in the city and cannot store and market the material. Besides the construction of new stations is also necessary to reform, equip and modernize existing to absorb the large amount of recyclables that can come if all the population starts to separate waste at home;

- Increase in the number of containers for voluntary delivery recyclable material;

- Increase in the number of trucks specific for the collection of recyclable materials;

- Creation of a new landfill with biogas, composting, mechanical central recyclable materials and a WTE (waste-to-energy) facility;

- Implement use of wood from trimming trees in the city by wood processing plants that can use this material in woodwork and for other organic compounds;

- To implement reverse logistics programs, noting that the National Policy of Solid Waste sets manufacturers, importers, distributors and retailers to be responsible for collecting and treating this parcel of waste. Post-consumer waste has to be delivered by citizens in available sites where it can be properly collected. Products that have priority in the reverse logistics system are electronics, batteries, fluorescent light bulbs, tires, pesticides and their packaging, lubricating oils and their packaging. Other recyclable packaging products should also participate in this system. For medicines it is already possible to discard them in private pharmacies and in public hospitals. In progress, there is a program to collect cooking oil called "Project Eco oil". Also underway is the collection of scrap tires, the goal is to collect a scrap tire for every new purchase;

- Promote the use of bulky objects discarded by the population such as furniture and appliances, in particular stations. [5]

There are some actions indicated in waste management related to environmental education:

- Disclosing to the citizens how to avail the waste generated in a home composting program entitled "Homemade Minicourse Horta and Composting";

- Encourage all public agencies purchase sustainable products, known as "Green Purchasing";

- Encourage all wood acquired it comes from sustainably managed;

- Encourage the use of products containing eco-labels (Green Seal) from ABNT (Brazilian Technical Standards Association);

- The Environmental Agenda of Public Administration (A3P Programme) which aims to produce products that save raw material, encouraging the use of efficient technologies and to enable the post-consumer recycling. [5]

To broaden public participation in the management of solid waste the City Hall aims to organize seminars, lectures, conferences, public hearings and other events with public agencies and universities to unite efforts to disseminate information and ensure greater public participation in this matter. [5]

To enable professionals working in the sorting of recyclable materials cooperatives was predicted creating two training centers, one has already been deployed in Butantã neighborhood and another must be built in accordance with the Integrated Solid Waste Management Plan in the city. [5] 


\section{RESULTS AND DISCUSSION}

Although the Solid Waste Management Plan from São Paulo to present all the objectives and guidelines necessary to compose an efficient management, it does not inform the sequence of actions, schedule of activities, coordination of different stakeholders and the planning and monitoring of each goal and guideline in detail. Despite very good goals, the total amount of waste going to landfills still increases every year. Thus, there is a need for a working group on the city council devoted to this activity in accordance with laws taken but not yet implemented.

With this in mind was created the Intersecretarial Committee for Solid Waste Municipal Policy, after several conferences and debates with public participation during 2013, was published the new version of PGIRS (Integrated Solid Waste Management Plan) in 2014. The PGIRS contains the actions to small, medium and long-term goals, but another document, Targets Plan of City Hall, indicates what the municipality intends to deliver to the population in the next four years. In addition, only four goals are related to the solid waste management topic, which are: Expand the municipal recyclables collection; Built 4 automated recyclable sorting plants; Deploy 84 new ecopoints and Promote composting of organic solid waste from about 900 street fairs and pruning services in the city. The goals indicated in the Targets Plan are included in the municipality budget for the period of 2013 to 2016, and then the next mayor will develop another Targets Plan. The problem is the discontinuity of actions from one government to another and the tenuous relation between both documents, PGIRS and Targets Plan.

São Paulo city needs to invest in infrastructure for the entire chain of solid waste management, from collection of the three main fractions: waste, recyclables and organic, to ensure that they have the most appropriate destination like recycling and composting and the creation of more voluntary delivery points of special waste and also recyclable.

Important to note is that the organic fraction still represents more than $50 \%$ of the gravimetric composition of household waste of a typical Brazilian [2,4], and may vary according to income; in poorer neighborhoods the organic fraction is usually higher than in wealthier neighborhoods. Therefore, to reduce the volume of waste sent to landfills it is necessary to invest in composting plants that can transform this waste into fertilizer and so divert it from landfills.

Currently the three fractions of solid waste are mixed and allocate in landfills, but both documents, the National Policy of Solid Waste and the PGIRS in São Paulo, indicated guidelines related to organic waste, thus this material could have another destination different from landfills soon. In the case of São Paulo city, it is indicated in the PGIRS to build composting plants in medium and long term. According the Targets Plan, related to actions in short term, is intend to provide the collection of waste from the street fairs for composting as well as encouraging the implementation of biodigesters located in shops, schools, supermarkets and residential condominiums. In addition, the municipality distributed 2,000 worm composter as an incentive to get more people sorting organic waste to composting. [5]

Moreover, it is crucial to include the scavengers in the solid waste management. According to the last demographic census (2010), 387,910 people declared themselves as scavengers in Brazil [11]. This number should be higher because part of population, working in informality, 
may have chosen not declare this information during the census survey, or having other complementary occupation, among other reasons. As reported by MNCR (National Movement of Scavengers of Recyclable Material) it is estimated that there are between 600 and 1 million scavengers in the country, which $9 \%$ are organized into cooperatives, $11 \%$ are in the process of organization and the rest, $80 \%$, are autonomous, working independently and informally [12]. In São Paulo there are 1,200 organized scavengers and probably, as they represent $10 \%$ of the total, maybe there are more than 12,000 autonomous scavengers in the city. [5]

Economy is another challenge. The fee for waste disposal at the landfill is still less than the cost of collecting recyclables. Therefore, it would be necessary to make the collection more efficient and recyclable in parallel to the increase of the rate of waste disposal in landfills. This economic engine will encourage recycling and composting and diverting increasingly these materials from landfill.

\section{CONCLUSIONS}

The correct disposal of solid waste is a serious problem faced by Brazilian cities, especially those who have not yet deployed a plan to manage their waste. There are many unresolved issues such as the insertion of scavengers and cooperatives in the system as a whole, recycling programs and reverse logistics, shared responsibility and fines for noncompliance with the actions indicated in the plan. Since these issues are not solved, parts of the Plan of Integrated Solid Waste Management of the municipality will be not reached. The proper inclusion of scavengers in the collection and sorting of recyclable materials process must be addressed. The renovation, expansion and construction of new units for sorting recyclable materials in order to increase the amount of this waste diverted from landfill is also extremely necessary. Such actions will generate income and formal employment for scavengers. Related policies to reverse logistics system have not yet been widely disseminated and implemented; only a few products are participating, returning to their manufacturers, in a continuous cycle.

Despite the lack of basic infrastructure to perform the collection, sorting and disposal of solid waste, Brazilian cities now, according to the National Policy of Solid Waste, has several duties to be implemented. Such as: to close their dumps, diverting recyclables and organic waste from landfill, implementing recycling and composting plants and only sending the residues (materials that is impossible reusing, recycling or composting) to landfill or waste-toenergy facilities. This is a legal milestone requiring a different position in relation to the current solid waste management and allow for long-term change, in society, in government and in the private sector, because each one is clearly responsible for the generation and proper disposal of municipal solid waste.

To conclude, it is extremely necessary that the society take part actively, sorting properly their waste in their homes and, the government along with the private sector invest in environmental awareness campaigns, reminding all population of the importance of their actions in the environment and public health. Only through environmental education, the objectives of the National Policy of Solid Waste will be completely achieved. 


\section{REFERENCES}

[1] IBGE, Brazilian Institute of Geography and Statistics, 2010. National Survey of Sanitation 2008. Rio de Janeiro: IBGE. (in Portuguese)

[2] ABRELPE, Brazilian Association of Public Cleaning and Special Waste, 2010.

Panorama of Solid Waste in Brazil. Available: <www.abrelpe.org.br/>. Access: Oct. 24, 2010. (in Portuguese)

[3] CEMPRE, Business Commitment to Recycling, 2012. Available:

<www.cempre.org.br/>. Access: Jun. 05, 2012. (in Portuguese)

[4] BRASIL. Law number 12.305, August 2, 2010. Establishing the National Solid Wastes; amending Law Number 9,605, of February 12, 1998; and other measures. (in Portuguese)

[5] PGIRS. Integrated Solid Waste Management Plan of São Paulo city, 2014. Available: < http://www.prefeitura.sp.gov.br/cidade/secretarias/upload/servicos/arquivos/PGIRS2014.pdf>. Access: Aug. 31, 2014. Reviewed version. (in Portuguese)

[6] PMSP. São Paulo City Hall, 2014. Available:< http://www.prefeitura.sp.gov.br/>. Access: Aug. 20, 2014. (in Portuguese)

[7] POLZER, V. R, 2012. Management of Solid Household waste in São Paulo and Vancouver. Dissertation (Master of Architecture and Urbanism) - Mackenzie University, São Paulo. (in Portuguese)

[8] BRASIL. Law number 13,522, of February 19, 2003. Provides about the organization of Urban Cleaning System in São Paulo. (in Portuguese)

[9] POLZER, V. R., 2011. Photos of Vergueiro transfer station and CTL landfill. São Paulo.

[10] POLZER, V. R., 2014. Photos of Caieiras landfill. Caieiras.

[11] IBGE, Brazilian Institute of Geography and Statistics, 2012. Demographic Census 2010. Available: <

http://www.ibge.gov.br/english/estatistica/populacao/censo2010/default.shtm>. Access: Aug. 31, 2014. (in English)

[12] MNCR, National Movement of Scavengers of Recyclable Material, 2014. Available: $<$ http://www.mncr.org.br>. Access: Aug. 31, 2014. (in Portuguese)

[13] BRAZIL, 2014. Brazil Federal government Portal. Available: < http://www.brasil.gov.br>. Access: Sep. 02, 2014. (in Portuguese) 